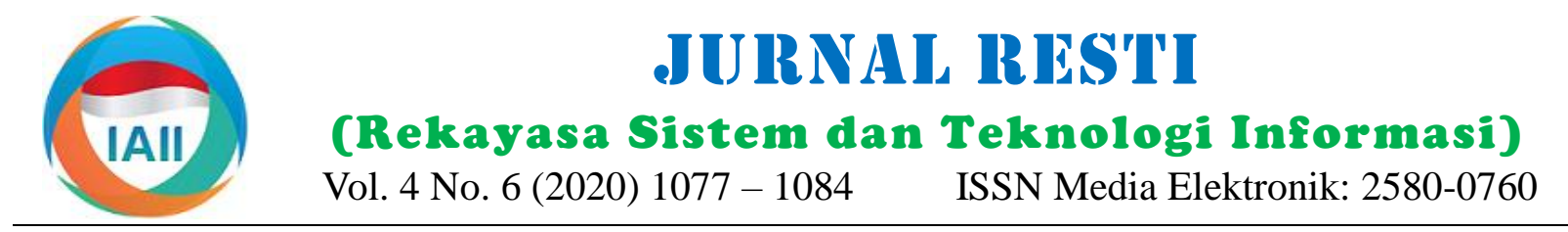

\title{
Perbandingan Metode Clustering dalam Pengelompokan Data Puskesmas pada Cakupan Imunisasi Dasar Lengkap
}

\author{
Pelsri Ramadar Noor Saputra ${ }^{1}$, Ahmad Chusyairi ${ }^{2}$ \\ ${ }^{1}$ Teknik Informatika, Informatika, Sekolah Tinggi Ilmu Komputer PGRI Banyuwangi \\ ${ }^{2}$ Teknik Informatika, Informatika, Universitas Bina Insani \\ ${ }^{1}$ ramayana.x@gmail.com, ${ }^{2}$ ahmadchusyairi@binainsani.ac.id
}

\begin{abstract}
The coverage of Health Care Center toward Universal Child Immunization (UCI) at Banyuwangi Regency in 2018 met the target $91 \%$. Unfortunately, with a high amount of immunization, the number of infant deaths reached 138 infants. Total number increased 111 from the previous year. A review of the complete basic immunization data needs to be done. In this research, a clustering method was proposed by comparing the K-Means and Fuzzy C-Means (FCM) algorithm in grouping Health Care Center data. Silhouette Coefficient and Standard Deviation were used to evaluate clusters that were performed to find out the accuracy in grouping data. The result showed that the FCM algorithm was better than K-Means based on Silhouette Coefficient results that were positive value, and the calculation of Standard Deviation had a smaller result that was 0.0918 than K-Means with the results of 0.0942. The Grouping of Heath Care Center data can be considered by the Health Department of Banyuwangi Regency in evaluating complete basic immunization services, especially in groups with poor immunization services to reduce infant and child mortality, so a disease that can be prevented with immunization become lower.
\end{abstract}

Keywords: clustering, fuzzy c-means, $k$-means, health care centers, silhouette coefficient

\begin{abstract}
Abstrak
Cakupan puskesmas terhadap Universal Child Immunization (UCI) di Kabupaten Banyuwangi tahun 2018 memenuhi target 91\%. Tetapi dengan cakupan imunisasi yang tinggi jumlah kematian bayi pada tahun 2018 mencapai 138 jiwa, meningkat dari tahun sebelumnya yang mencapai 111 jiwa. Maka perlu dilakukan kajian kembali terhadap data Imunisasi Dasar Lengkap (IDL) oleh puskesmas. Dalam penelitian ini diusulkan metode clustering dengan mengkomparasi algoritma K-Means dan Fuzzy C-Means (FCM) Clustering dalam pengelompokan data puskesmas. Dalam mengevaluasi hasil cluster yang terbentuk, digunakan metode Silhouette Coefficient serta Standard Deviation untuk mengetahui ketepatan dalam pengelompokan data. Didapatkan bahwa hasil pengelompokan algoritma FCM lebih baik berdasarkan nilai Silhouette Coefficient yang memiliki nilai positif dibandingkan K-Means yang memiliki nilai minus, serta perhitungan Standard Deviation memiliki hasil lebih kecil yaitu 0.0918 daripada K-Means dengan hasil 0.0942. Pengelompokan data puskesmas ini dapat menjadi masukan bagi dinas kesehatan Kabupaten Banyuwangi dalam mengevaluasi pelayanan IDL terutama pada kelompok puskesmas dengan layanan imunisasi rendah guna menekan angka kematian bayi dan anak sehingga Penyakit yang Dapat Dicegah Dengan Imunisasi (PD3I) menjadi lebih rendah.
\end{abstract}

Kata kunci: clustering, fuzzy c-means, k-means, puskesmas, silhouette coefficient.

\section{Pendahuluan}

World Health Organization (WHO) menetapkan program imunisasi secara global pada tahun 1974 sebagai komponen penting bagi pelayanan kesehatan ibu dan anak, terutama kesehatan primer [1]. Imunisasi Dasar Lengkap (IDL) merupakan salah satu cara dalam mengurangi angka kematian bayi dan anak dikarenakan imunisasi bertujuan dalam meningkatkan kekebalan tubuh dan menghindari resiko Penyakit yang Dapat
Dicegah Dengan Imunisasi (PD3I) seperti campak, hepatitis, tuberkolosis, dan sebagainya [2]. Berdasarkan data dari Kementrian Kesehatan RI tahun 2018 melaporkan bahwa imunisasi dasar lengkap di Indonesia sebesar 90,61\%. Angka ini sedikit di bawah target renstra (rencana strategis) Kementrian Kesehatan sebesar $92,5 \%$ yang ditetapkan [3]. Banyak faktor yang menyebabkan target belum tercapai antara lain: pengetahuan ibu, status ekonomi, dukungan keluarga, serta penyuluhan dari tenaga kesehatan [4], [5]. 
Pencapaian Universal Child Imunization (UCI) kedisiplinan karyawan. Penelitian yang dilakukan oleh merupakan gambaran cakupan imunisasi lengkap pada Ramadhan, Efendi, serta Mustakim [18] dalam bayi dan anak yang merupakan upaya perlindungan pengelompokan data User Knowledge Modelling, sedini mungkin terhadap penularan PD3I dengan target dimana dari kedua penelitian tersebut dilakukan $\geq 80 \%$. Cakupan puskesmas terhadap UCI di Kabupaten perbandingan terhadap algoritma K-Means dengan FCM Banyuwangi pada tahun 2018 memenuhi target 91\% [6]. Clustering. Dipergunakan metode Sillhouette Akan tetapi dengan cakupan imunisasi yang tinggi Coefficient Untuk menghitung tingkat keakurasian jumlah kematian bayi pada tahun 2018 mencapai 138 kedua metode tersebut.

jiwa, meningkat dari tahun sebelumnya yang mencapai 111 jiwa [7].

Penelitian yang diangkat oleh Rodiyansyah [13] yaitu menganalisa data polusi udara pada suatu perkotaan.

Hal ini dibuktikan dengan diterbitkan keputusan oleh Sebagai proses analisis cluster data polusi udara harian Bupati Banyuwangi dengan nomor berdasarkan hari, waktu, dan beban polutan yang 188/34/KEP/429.011/2018 mengenai penetapan mengandung zat kimia berbahaya. Dari hasil kaji Kejadian Luar Biasa (KLB) difteri [8]. Dari banding antara FCM dengan K-Means, dipergunakan permasalahan tersebut, perlu dilakukan kajian kembali perhitungan Standard Deviation dalam tingkat terhadap data IDL yang dilaksanakan oleh setiap keakurasian dari kedua metode yang diusulkan.

puskesmas. Data yang dipergunakan merupakan data unsupervised, sehingga diusulkan metode clustering di dalam penelitian ini dengan mengkomparasi algoritma K-Means dan Fuzzy C-Means Clustering dalam pengelompokan data puskesmas.

Maka penelitian ini berfokus dalam pengelompokan data puskesmas menggunakan algoritma $K$-Means dan FCM, Metode Silhouette Coefficient serta Standard Deviation digunakan dalam perbandingan kedua metode yang digunakan dan mengevaluasi hasil cluster yang Clustering merupakan proses pengelompokan terbentuk. Silhouette Coefficient merupakan metode berdasarkan persamaan anggota pada setiap partisi evaluasi dalam menguji hasil clustering yang terbentuk. dalam matriks tertentu [9]. Berdasarkan analisa cluster Metode ini merupakan gabungan dari metode separation memiliki tujuan mengelompokan $n$ objek atau individu dan cohesion [19]. Hasil terbaik dari pengujian kedua kedalam beberapa $m$ kluster berdasarkan metode yang diusulkan diharapkan dapat menjadi usulan karakteristiknya [10], sehingga cluster memiliki sifat dan masukan bagi dinas kesehatan Kabupaten berbeda antar kelompok, sedangkan setiap kelompoknya Banyuwangi dalam mengevaluasi pelayanan IDL memiliki sifat relatif homogen. Dalam menganalisa data terutama pada kelompok puskesmas dengan layanan dibutuhkan beberapa proses antara lain: standarisasi imunisasi rendah guna menekan angka kematian bayi data, pengukuran kemiripan objek, dan pemilihan dan anak dalam PD3I menjadi lebih rendah. prosedur analisis cluster [11].

K-Means merupakan bagian dari metode clustering dengan teknik unsupervised yang mempartisi data 2. Metode Penelitian

kedalam dua atau lebih kelompok [12] dengan konsep Normalisasi data digunakan untuk menskalakan nilai dasar data yang semakin mendekati pusat cluster, maka data dalam rentang yang ditentukan dalam memudahkan data adalah bagian dari cluster tersebut [13]. Proses tahapan-tahapan perhitungan seperti perhitungan dalam K-Means secara acak memilih sejumlah pusat kesamaan atau operasi clustering [20]. Salah satu cluster sesuai dengan jumlah cluster yang ditentukan. metode normalisasi adalah metode Min-Max yang Dalam tiap iterasinya dihitung keanggotaan data merupakan teknik sederhana dalam penskalaan nilai terhadap pusat cluster baru. Proses akan berhenti apabila berdasarkan batas-batas yang ditentukan [21]. pusat cluster serta keanggotaan data tidak berubah [14]. Persamaan Min-Max ditunjukkan sebagai berikut:

Sedangkan Fuzzy C-Means (FCM) merupakan metode cluster dengan konsep mengelompokkan data $X_{i}=\frac{X-X_{\min }}{X_{\max }-X_{\min }}$ berdasarkan derajat keanggotaan data. FCM bersifat soft clustering karena berdasarkan pada logika fuzzy, sebuah Tahapan metode Min-Max dilakukan dengan mencari data dapat menjadi bagian dari dua atau lebih cluster nilai terkecil dan terbesar dalam dataset layanan dengan bobot keanggotaan berkisar antara 0 dan 1 [15], imunisasi puskesmas terlebih dahulu, dengan persamaan [16]. Proses FCM menghitung jarak antara pusat cluster (1) metode ini akan menghasilkan dataset baru dengan dengan setiap data, sehingga dapat ditetapkan rentang nilai dari 0 hingga 1.

keanggotaan semua titik data terhadap tiap pusat cluster.

Penelitian terdahulu dalam perbandingan algoritma $K$ Means dan FCM yang dilakukan oleh Agustina dan Prihandoko [17] membahas mengenai tingkat kedisiplinan kinerja karyawan di Sekolah Tinggi Teknologi (STT) Bandung dengan mengevaluasi tingkat

\subsection{K-Means Clustering}

Langkah-langkah dalam penyelesaian cluster menggunakan K-Means adalah set jumlah cluster yaitu tiga cluster serta maksimum iterasi yaitu 100. Selanjutnya tentukan titik pusat cluster awal (centroid

Jurnal RESTI (Rekayasa Sistem dan Teknologi Informasi) Vol. 4 No. 6 (2020) 1077 - 1084 
awal) secara acak dari normalisasi dataset imunisasi. $S_{i}=\frac{\left(b_{i}-a_{i}\right)}{\max \left(b_{i}-a_{i}\right)}$
hitung jarak tiap data terhadap pusat cluster untuk

mencari jarak terdekat menggunakan Eucledian

Distance dengan persamaan [18]:

$d\left(x_{i}, \mu_{i}\right)=\sqrt{\left(x_{i}, \mu_{i}\right)^{2}+\cdots+\left(x_{n}, \mu_{n}\right)^{2}}$

Didapatkan kelompok tiap data berdasarkan jarak terdekat dari tiap cluster. Kemudian hitung nilai Within Centroid Variance (WCV) yaitu rata-rata nilai data tiap cluster dengan persamaan:

$C_{k}=\frac{1}{n_{k}} \sum d_{i}$

Hitung nilai Between Cluster Variance (BCV) berdasarkan nilai rata-rata yang didapat dari kelompok tiap cluster yang didapat dari persamaan (2). Kemudian hitung nilai rasio dengan rumus Rasio $=\mathrm{BCV} / \mathrm{WCV}$. Proses $K$-Means akan berhenti apabila keanggotaan data tiap cluster tidak berubah atau nilai rasio dalam iterasi lebih kecil sama dengan nilai rasio pada iterasi sebelumnya. Jika tidak, maka lanjut iterasi dengan mengeset nilai pusat cluster dengan nilai rata-rata dari kelompok cluster yang didapat.

\subsection{Fuzzy C-Means}

Langkah-langkah yang dilakukan pada algoritma Fuzzy C-Means adalah ditentukan jumlah cluster sebanyak 3 cluster, error terkecil yang diharapkan epsilon $(\varepsilon)$ yaitu 0.0001 , nilai maksimum iterasi, dan nilai matriks partisi awal tiap data pada setiap cluster secara acak. Hitung jumlah setiap data pada normalisasi dataset imunisasi dengan data matriks partisi awal dengan persamaan:

$Q_{i}=\sum_{k=1}^{c} \mu_{i k}$

$\mu_{i k}=\frac{\mu_{i k}}{Q_{i}}$

dari derajat keanggotaan ketiga cluster tersebut, hitung nilai rata-rata tiap cluster untuk mendapatkan nilai pusat cluster. Kemudian hitung nilai rata-rata fungsi objectif antara data normalisasi imunisasi dengan pusat cluster dengan persamaan:

$\left.P_{t}=\sum_{i=1}^{n} \sum_{k=1}^{c}\left(\left[\sum_{j=1}^{m}\left(X_{i j}-V_{k j}\right)^{2}\right] \mu_{i k}\right)^{w}\right)$

Proses FCM akan berhenti apabila nilai fungsi objektif dikurangin nilai fungsi objektif iterasi sebelumnya kurang dari sama dengan nilai eplison atau maksimum iterasi telah tercapai.

\subsection{Silhouette Coefficient}

Dari hasil cluster yang telah terbentuk pada $K$-Means dan FCM, maka selanjutnya digunakan Silhouette Coefficient untuk menghitung ketepatan pada pengelompokan data. Rumus yang dipergunakan dalam perhitungan Silhouette Coefficient didefinisikan dengan persamaan sebagai berikut [22]:
Dimana $a_{i}$ merupakan rata-rata jarak objek $i$ dengan seluruh objek dalam sebuah cluster, sedangkan $b_{i}$ adalah nilai terkecil rata-rata objek $i$ dengan objek pada cluster yang berbeda. Nilai yang dihasilkan oleh perhitungan Silhouette Coefficient adalah -1 hingga 1 [18]. Hasil ratarata $S_{i}$ untuk seluruh data dalam sebuah cluster menunjukkan ketepatan dalam pengelompokan data. Semakin mendekati 1, struktur clustering yang dihasilkan tepat, jika -1 maka struktur clustering yang dihasilkan overlapping. Dari hasil perhitungan Silhouette Coefficient terhadap hasil cluster K-Means dan FCM akan dibandingkan untuk mencari hasil pengelompokan data terbaik dari kedua metode tersebut.

\subsection{Lingkup Penelitian}

Penelitian yang dilakukan berfokus dalam perbandingan terhadap dua metode clustering yaitu Fuzzy C-Means dan $K$-Means clustering dengan mempergunakan data imunisasi anak dari tahun 2017 hingga 2019 yang didapatkan secara langsung dari dinas kesehatan Kabupaten Banyuwangi. Data puskesmas beserta jumlah pelayanan imunisasi per tahunnya ditunjukkan pada tabel 1. Data ini merupakan data yang dicatat berdasarkan hasil akumulasi pemberian imunisasi bagi balita dan anak yang dilakukan oleh setiap puskesmas dalam setiap tahunnya.

Data yang didapat merupakan hasil dari kebijakan program Jaminan Pelayanan Kesehatan Masyarakat Banyuwangi (JPKMB) dalam pelayanan kesehatan primer bagi seluruh lapisan masyarakat melalui puskesmas [23]. 45 data puskesmas akan dikelompokkan berdasarkan tingkat pemberian imunisasi, yaitu data puskesmas dengan pemberian imunisasi tinggi, data puskesmas dengan pemberian imunisasi sedang, dan data puskesmas dengan pemberian imunisasi rendah.

Tabel 1. Data Imunisasi Puskesmas Kabupaten Banyuwangi

\begin{tabular}{clrrr}
\hline \multirow{2}{*}{ No } & \multirow{2}{*}{ Data Puskesmas } & \multicolumn{3}{c}{ Data Imunisasi } \\
\cline { 3 - 5 } & & $\mathbf{2 0 1 7}$ & $\mathbf{2 0 1 8}$ & \multicolumn{1}{c}{$\mathbf{2 0 1 9}$} \\
\hline 1 & Wongsorejo & 1,916 & 1,901 & 1,875 \\
2 & Bajulmati & 1,742 & 1,727 & 1,703 \\
3 & Kelir & 927 & 923 & 910 \\
4 & Klatak & 3,070 & 3,067 & 3,024 \\
5 & Mojopanggung & 1,390 & 1,374 & 1,355 \\
6 & Paspan & 1,644 & 1,624 & 1,614 \\
7 & Licin & 1,347 & 1,333 & 1,321 \\
8 & Sobo & 2,167 & 2,135 & 2,107 \\
9 & Singotrunan & 1,748 & 1,724 & 1,706 \\
10 & Kertosari & 1,169 & 1,150 & 1,136 \\
11 & Kabat & 2,777 & 2,752 & 2,722 \\
12 & Badean & 2,406 & 2,379 & 2,348 \\
13 & Gitik & 1,603 & 1,586 & 1,574 \\
14 & Gladag & 890 & 882 & 872 \\
15 & Singojuruh & 2,127 & 2,102 & 2,090 \\
16 & Songgon & 2,358 & 2,323 & 2,300 \\
17 & Kebaman & 1,274 & 1,255 & 1,240 \\
18 & Parijatah Kulon & 1,362 & 1,345 & 1,330 \\
19 & Wonosobo & 1,533 & 1,512 & 1,492 \\
20 & Kedungrejo & 1,814 & 1,791 & 1,768
\end{tabular}




\begin{tabular}{llrrr}
\hline \multirow{2}{*}{ No } & \multirow{2}{*}{ Data Puskesmas } & \multicolumn{3}{c}{ Data Imunisasi } \\
\cline { 3 - 5 } & 2017 & $\mathbf{2 0 1 8}$ & $\mathbf{2 0 1 9}$ \\
\hline 21 & Sumberberas & 1,412 & 1,397 & 1,379 \\
22 & Tapanrejo & 1,017 & 1,004 & 994 \\
23 & Tembokrejo & 2,004 & 1,979 & 1,954 \\
24 & Tegaldlimo & 1,674 & 1,647 & 1,629 \\
25 & Kedungwungu & 1,237 & 1,222 & 1,207 \\
26 & Purwoharjo & 1,634 & 1,608 & 1,589 \\
27 & Grajagan & 1,439 & 1,419 & 1,404 \\
28 & Benculuk & 2,080 & 2,053 & 2,030 \\
29 & Tampo & 1,259 & 1,244 & 1,232 \\
30 & Jajag & 1,357 & 1,342 & 1,326 \\
31 & Yosomulyo & 1,447 & 1,430 & 1,411 \\
32 & Tegalsari & 2,214 & 2,194 & 2,170 \\
33 & Genteng Kulon & 2,206 & 2,177 & 2,150 \\
34 & Kembiritan & 1,780 & 1,758 & 1,738 \\
35 & Sempu & 1,496 & 1,476 & 1,459 \\
36 & Karangsari & 1,477 & 1,458 & 1,437 \\
37 & Gendoh & 408 & 401 & 395 \\
38 & Sepanjang & 1,839 & 1,817 & 1,795 \\
39 & Tulungrejo & 1,476 & 1,458 & 1,441 \\
40 & Kalibaru Kulon & 2,967 & 2,934 & 2,898 \\
41 & Kebondalem & 1,457 & 1,434 & 1,417 \\
42 & Sambirejo & 1,368 & 1,351 & 1,332 \\
43 & Pesanggaran & 987 & 976 & 962 \\
44 & Sumberagung & 1,325 & 1,311 & 1,292 \\
45 & Siliragung & 2,115 & 2,082 & 2,055 \\
\hline
\end{tabular}

Berdasarkan hasil pengelompokan kedua metode yang diusulkan, hasil pengelompokan yang terbaik akan menjadi rujukan bagi dinas kesehatan Kabupaten Banyuwangi untuk mendorong puskesmas dengan layanan imunisasi sedang dan rendah untuk meningkatkan pelayanannya terhadap masyarakat, terutama bagi kesehatan masa depan anak-anak.

\subsection{Tahapan Penelitian dan Perancangan Sistem}

Desain dalam tahapan-tahapan penelitian ini ditunjukkan pada gambar 1 dimana pembahasannya adalah persiapan data dari puskesmas mengenai pelaksanaan imunisasi bayi dan anak.

Kemudian dibuatkan perancangan sistem dalam pengelompokan data puskesmas yang membahas mengenai inisialisasi data awal untuk kedua metode clustering. Selanjutnya pengujian data imunisasi dengan metode K-Means dan Fuzzy C-Means Clustering.

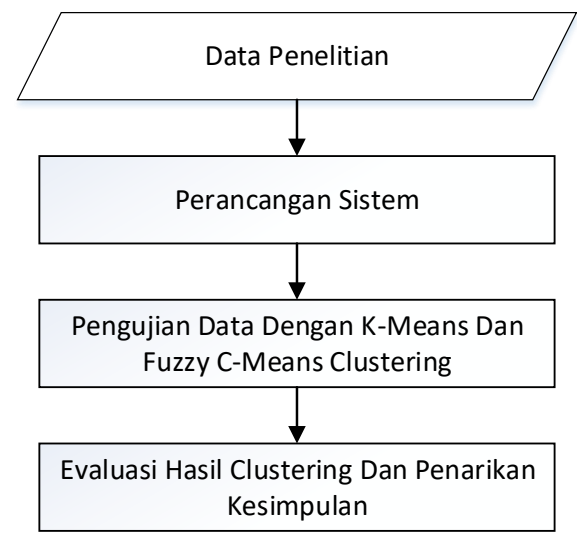

Gambar 1. Tahapan Penelitian
Perancangan sistem secara umum ditunjukkan pada gambar 2 dimana penjabarannya adalah pertama kali disiapkan data imunisasi untuk selanjutnya dilakukan proses normalisasi data menggunakan metode Min-Max.

Tujuan dalam normalisasi ini adalah untuk mempermudah proses perhitungan. Selanjutnya ditentukan inisialisasi data awal baik bagi algoritma $K$ Means mauun Fuzzy C-Means.

Data normalisasi selanjutnya diproses dengan menggunakan kedua algoritma di atas. Setelah proses pengelompokan selesai dilakukan, maka hasil clustering akan dilakukan validasi cluster dengan mempergunakan metode Silhoutte Coefficient dan Standard Deviation.

Hasil evaluasi dari kedua metode tersebut akan dikomparasi sebagai penarik kesimpulan untuk menentukan hasil clustering mana yang terbaik dalam pengelompokan data puskesmas dalam pemberian imunisasi bayi dan anak.

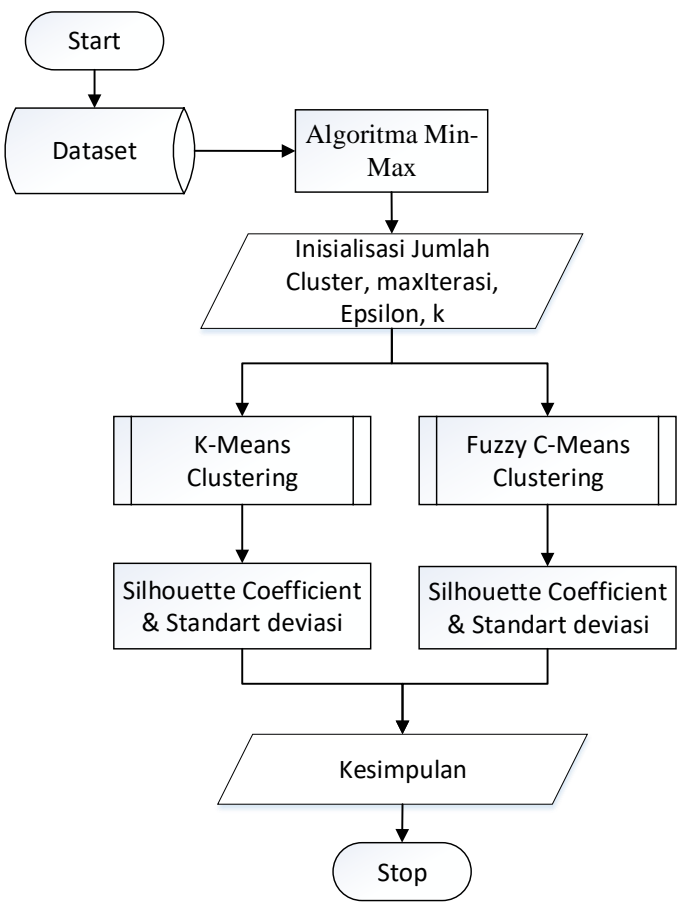

Gambar 2. Perancangan Sistem Sesuai Tahapan Penelitian

\section{Hasil dan Pembahasan}

\subsection{Normalisasi Data}

Dari dataset yang ditunjukkan pada tabel 1 dinormalisasikan dengan menggunakan algoritma MinMax. pencarian nilai terkecil dan terbesar diperlukan untuk proses perhitungan Min-Max, dan dihasilkan bahwa nilai terkecil dari dataset adalah 395, dan nilai terbesar adalah 3070. Proses perhitungan dilakukan dengan menggunakan persamaan (1), dan hasil penormalisasian data ditunjukkan pada tabel 2 . 
Tabel 2. Normalisasi Data Imunisasi

\begin{tabular}{clccc}
\hline \multirow{2}{*}{ No } & \multirow{2}{*}{ Data Puskesmas } & \multicolumn{3}{c}{ Data Pasien } \\
\cline { 3 - 5 } & & $\mathbf{2 0 1 6}$ & $\mathbf{2 0 1 7}$ & $\mathbf{2 0 1 8}$ \\
\hline 1 & Wongsorejo & 0.57 & 0.56 & 0.55 \\
2 & Bajulmati & 0.50 & 0.50 & 0.49 \\
3 & Kelir & 0.20 & 0.20 & 0.19 \\
4 & Klatak & 1.00 & 1.00 & 0.98 \\
5 & Mojopanggung & 0.37 & 0.37 & 0.36 \\
6 & Paspan & 0.47 & 0.46 & 0.46 \\
$\ldots$ & $\ldots$ & $\ldots$ & $\ldots$ & $\ldots$ \\
$\ldots$ & $\ldots$ & $\ldots$ & $\ldots$ & $\ldots$ \\
43 & Pesanggaran & 0.22 & 0.22 & 0.21 \\
44 & Sumberagung & 0.35 & 0.34 & 0.34 \\
45 & Siliragung & 0.64 & 0.63 & 0.62 \\
\hline
\end{tabular}

\subsection{Inisialisasi Awal}

Dilakukan inisialisasi awal sebelum masuk kedalam tahap proses clustering pada kedua algoritma yang diusulkan. Inisialisasi diperlukan untuk penentuan hasil cluster data puskesmas.

Data inisialisasi awal ditunjukkan pada tabel 3. Data puskesmas akan dibagi menjadi 3 cluster guna menentukan data puskesmas dengan pelayanan imunisasi bagus, pelayanan imunisasi sedang, dan pelayanan imunisasi rendah. Maksimal iterasi yang dipergunakan kedua metode clustering sebesar 100.

Tabel 3. Inisialisasi Awal

\begin{tabular}{clc}
\hline & Nama & Nilai \\
\hline & Data Cluster & 3 \\
& Maximal Iterasi & 100 \\
\hline K-Means & Pusat Cluster Awal & (random) \\
\hline \multirow{3}{*}{ FCM } & Error Terkecil & $10^{-5}$ \\
& Pangkat & 2 \\
& Matrix Partisi awal & (random) \\
\hline
\end{tabular}

Kemudian untuk metode Fuzzy C-Means akan ditentukan nilai error terkecil yang diharapkan sebesar 0.00001 , dan nilai pangkat adalah 2. Kemudian dibuatkan tiga data matriks partisi awal yang didapatkan secara acak untuk tiap data puskesmas dengan rentang nilai data 0-1. Dan penjumlahan dari ketiga nilai data pada tiap puskesmas akan menghasilkan nilai 1 .

\subsection{Perhitungan Fuzzy C-Means Clustering}

Tahapan dalam perhitungan menggunakan Fuzzy CMeans pada iterasi I adalah pertama kali dilakukan pengesetan tiga nilai partisi awal secara random dengan rentang nilai 0-1 dengan total ketiga nilai harus sama dengan 1, Hal ini dimaksudkan agar hasil pengelompokan data stabil. Nilai partisi awal dijabarkan pada tabel 4.

Tabel 4. Matrix Partisi Awal

\begin{tabular}{ccccc}
\hline Puskesmas & $\mathbf{X 1}$ & $\mathbf{X} 2$ & $\mathbf{X 3}$ & Total X \\
\hline 1 & 0.024 & 0.538 & 0.438 & 1 \\
2 & 0.331 & 0.436 & 0.232 & 1 \\
3 & 0.016 & 0.641 & 0.343 & 1 \\
$\ldots$ & $\ldots$ & $\ldots$ & $\ldots$ & $\ldots$ \\
$\ldots$ & $\ldots$ & $\ldots$ & $\ldots$ & $\ldots$ \\
45 & 0.078 & 0.351 & 0.571 & 1 \\
\hline
\end{tabular}

Nilai pada tabel 4 digunakan dalam perhitungan pusat cluster dengan menghitung derajat keanggotaan cluster. Pusat cluster ditunjukkan pada tabel 5.

Tabel 5. Hasil Pusat Cluster

\begin{tabular}{cccc}
\hline Cluster & X1 & X2 & X3 \\
\hline C1 & 0.492 & 0.484 & 0.477 \\
C2 & 0.484 & 0.477 & 0.469 \\
C3 & 0.443 & 0.436 & 0.429 \\
\hline
\end{tabular}

Hitung perubahan matriks partisi dalam menentukan keanggotaan tiap data puskesmas. Selanjutnya hitung fungsi objective. Didapatkan total nilai fungsi objective sebesar 2.276.

Nilai fungsi objective akan menentukan apakah iterasi akan berhenti atau berlanjut dengan membandingkan terhadap nilai error terkecil yang diharapkan. Nilai yang didapat masih lebih besar dari nilai error terkecil yaitu 10-5, maka iterasi berlanjut dan nilai perubahan partisi akan digunakan sebagai perhitungan partisi pada iterasi selanjutnya.

Proses perhitungan Fuzzy C-Means berhenti pada iterasi ke-32 dimana didapatkan nilai fungsi objective sebesar 0.000009. Pengelompokan data puskesmas menggunakan FCM ditunjukkan pada tabel 6.

Tabel 6. Pengelompokan Data Fuzzy C-Means

\begin{tabular}{lll}
\hline \multicolumn{1}{c}{ Cluster 1 } & \multicolumn{1}{c}{ Cluster 2 } & \multicolumn{1}{c}{ Cluster 3 } \\
\hline Klatak & Wongsorejo & Kelir \\
Sobo & Bajulmati & Mojopanggung \\
Kabat & Paspan & Licin \\
Badean & Singotrunan & Kertosari \\
Singojuruh & Gitik & Gladag \\
Songgon & Wonosobo & Kebaman \\
Tembokrejo & Kedungrejo & Parijatah Kulon \\
Benculuk & Tegaldlimo & Sumberberas \\
Tegalsari & Purwoharjo & Tapanrejo \\
Genteng Kulon & Kembiritan & Kedungwungu \\
Kalibaru Kulon & Sepanjang & Grajagan \\
Siliragung & & Tampo \\
& & Jajag \\
& & Yosomulyo \\
& & Sempu \\
& & Karangsari \\
& & Gendoh \\
& & Tulungrejo \\
& & Kebondalem \\
& & Sambirejo \\
& & Pesanggaran \\
& & Sumberagung \\
\hline & &
\end{tabular}

\subsection{Perhitungan K-Means Clustering}

Tahapan perhitungan K-Means pada iterasi I dilakukan dengan menghitung jarak tiap data terhadap pusat cluster dengan persamaan (2). Maka dapat diketahui jarak terdekat setiap data terhadap setiap centroid yang menjadi acuan dalam pengelompokan data. Hitung nilai WCV dengan menjumlahkan tiap data nilai terkecil pangkat 2. Hasil nilai WCV ditunjukkan pada tabel 7. 


\begin{tabular}{|c|c|c|c|c|c|}
\hline Puskesmas & C1 & C2 & $\mathrm{C3}$ & $\begin{array}{c}\text { Min } \\
\text { Jarak }\end{array}$ & $\begin{array}{c}\text { Min }_{\text {Jarak }^{\wedge 2}} \\
\end{array}$ \\
\hline 1 & 0.111 & 0.053 & 0.285 & 0.053 & 0.003 \\
\hline 2 & 0.003 & 0.165 & 0.173 & 0.003 & 0.000 \\
\hline 3 & 0.522 & 0.686 & 0.348 & 0.348 & 0.121 \\
\hline 4 & 0.860 & 0.696 & 1.034 & 0.696 & 0.484 \\
\hline$\cdots$ & $\cdots$ & $\cdots$ & $\cdots$ & $\ldots$ & $\cdots$ \\
\hline \multirow[t]{2}{*}{45} & 0.232 & 0.068 & 0.406 & 0.068 & 0.005 \\
\hline & & & & WCV & 2.369 \\
\hline
\end{tabular}

Hitung jarak antar cluster yang didapatkan berdasarkan total nilai minimal jarak yang telah didapatkan dari perhitungan jarak data terhadap centroid yang nantinya akan dipergunakan dalam mencari nilai BVC. Perhitungan antar cluster ditampilkan pada tabel 8.

Tabel 8. Nilai BCV

\begin{tabular}{cc}
\hline Cluster & Jarak \\
\hline $1-2$ & 0.1636 \\
$1-3$ & 0.1740 \\
$2-3$ & 0.3376 \\
\hline BVC & $\mathbf{0 . 6 7 5 2}$ \\
\hline
\end{tabular}

Hitung nilai rasio berdasarkan nilai BVC dan WCV.

$$
\text { Rasio }=\mathrm{BCV} / \mathrm{WCV}=0.6752 / 2.369=0.285
$$

Karena masih iterasi I, maka lanjut ke iterasi II. Lakukan proses perhitungan sama seperti iterasi I dan cari nilai rasio kembali. Dilakukan perbandingan nilai rasio pada iterasi II dengan iterasi I. jika nilai rasio Iterasi II lebih kecil sama dengan nilai rasio iterasi I, maka proses clustering telah selesai, selain itu lanjut iterasi. Perhitungan berhenti pada iterasi IV dimana nilai rasio telah terpenuhi dan keanggotaan cluster tidak berubah. Hasil pengelompokan data ditampilkan pada tabel 9.

Tabel 9. Pengelompokan Data K-Means

\begin{tabular}{lll}
\hline \multicolumn{1}{c}{ Cluster 1 } & \multicolumn{1}{c}{ Cluster 2 } & \multicolumn{1}{c}{ Cluster 3 } \\
\hline Wongsorejo & Klatak & Kelir \\
Bajulmati & Sobo & Mojopanggung \\
Paspan & Kabat & Licin \\
Singotrunan & Badean & Kertosari \\
Gitik & Singojuruh & Gladag \\
Wonosobo & Songgon & Kebaman \\
Kedungrejo & Benculuk & Parijatah Kulon \\
Tembokrejo & Tegalsari & Sumberberas \\
Tegaldlimo & Genteng Kulon & Tapanrejo \\
Purwoharjo & Kalibaru Kulon & Kedungwungu \\
Kembiritan & Siliragung & Grajagan \\
Sepanjang & & Tampo \\
& & Jajag \\
& & Yosomulyo \\
& & Sempu \\
& & Karangsari \\
& & Gendoh \\
& & Tulungrejo \\
& & Kebondalem \\
& & Sambirejo \\
& & Pesanggaran \\
& & Sumberagung \\
\hline
\end{tabular}

\subsection{Hasil Analisis}

Dari data cluster yang didapatkan dari hasil perhitungan FCM dan $K$-Means pada tabel 6 dan 9, terlebih dahulu akan ditentukan kelompok data puskesmas dengan pelayanan imunisasi tinggi, sedang, dan rendah dengan menghitung rata-rata nilai tiap kelompok. Hasil pengelompokan data ditampilkan pada tabel 10 .

Tabel 10. Pengelompokan Data Puskesmas

\begin{tabular}{ccc}
\hline \multicolumn{2}{c}{ FCM } \\
\hline Cluster Ke- & Nilai & Keanggotaan \\
\hline 1 & 0.730 & Tinggi \\
2 & 0.488 & Sedang \\
3 & 0.314 & Rendah \\
\hline \multicolumn{3}{c}{ K-Means } \\
\hline Cluster Ke- & Nilai & Keanggotaan \\
\hline 1 & 0.497 & Sedang \\
2 & 0.742 & Tinggi \\
3 & 0.314 & Rendah \\
\hline
\end{tabular}

Pengelompokan dari algoritma $K$-Means pada tabel 6 menunjukkan bahwa pada cluster 1 terdapat 12 data puskesmas sebagai cluster dengan layanan imunisasi sedang. Pada cluster 2 terdapat 11 data puskesmas sebagai cluster dengan layanan imunisasi tinggi. Cluster 3 sebagai layanan imunisasi rendah memiliki 22 data puskesmas. Pengelompokan dari algoritma FCM pada tabel 9 menunjukkan bahwa pada cluster 1 terdapat 12 data sebagai cluster dengan layanan imunisasi tinggi. Pada cluster 2 terdapat 11 data puskesmas sebagai cluster dengan layanan imunisasi sedang. Sedangkan Cluster 3 memiliki data yang sama dengan hasil $K$ Means sebanyak 22 data puskesmas.

Dari kelompok data yang dihasilkan dari kedua algoritma tersebut, perbedaan terdapat pada kelompok puskesmas dengan layanan imunisasi tinggi dan sedang pada cluster 1 dan 2 .

Kemudian dilakukan perhitungan Silhouette Coefficient terhadap hasil kelompok data dari kedua metode tersebut. Selain itu, digunakan perhitungan Standard Deviation untuk meyakinkan hasil yang diperoleh. Hasil perhitungan ditunjukkan pada tabel 11 dan 12 . Berdasarkan hasil perhitungan Silhouette Coefficient pada tabel 11 menunjukkan bahwa hasil FCM memiliki nilai yang lebih baik dibandingkan dengan $K$-Means.

Tabel 11. Perhitungan Sillhouette Coefficient

\begin{tabular}{clc}
\hline No & Algoritma & Silhouette Coefficient \\
\hline 1 & FCM & 0.1287696 \\
2 & K-Means & -0.1182356 \\
\hline
\end{tabular}

Tabel 12. Perhitungan Standard Deviation

\begin{tabular}{|c|c|c|c|c|c|}
\hline \multirow{2}{*}{ No } & \multirow{2}{*}{ Algoritma } & \multicolumn{3}{|c|}{ Cluster } & \multirow{2}{*}{$\begin{array}{c}\text { Rata-Rata } \\
\text { Standar } \\
\text { Deviasi }\end{array}$} \\
\hline & & 1 & 2 & 3 & \\
\hline 1 & K-Means & 0.1350 & 0.0505 & 0.0970 & 0.0942 \\
\hline 2 & FCM & 0.1358 & 0.0425 & 0.0970 & 0.0918 \\
\hline
\end{tabular}


Begitu pula hasil perhitungan Standard Deviation pada Daftar Rujukan

tabel 12, nilai FCM lebih kecil dibandingkan dengan $K$ -

Means. Pengaruh data puskesmas pada cluster 1 dan 2 tiap algoritma memiliki pengaruh yang signifikan dalam penentuan kelompok puskesmas yang tepat.

Hasil pengelompokan data puskesmas dari penelitian ini selanjutnya dikoordinasikan kepada dinas kesehatan Banyuwangi dan bersama-sama dilakukan penyuluhan dan monitoring terhadap kegiatan pemberian imunisasi dasar lengkap kepada puskesmas terutama puskesmas dengan tingkat menengah dan rendah.

\section{Kesimpulan}

Kesimpulan dari penelitian ini adalah nilai dari perhitungan Silhouette Coefficient menunjukkan bahwa algoritma FCM memiliki nilai positif sebesar 0.129 sedangkan $K$-Means memiliki nilai negatif yaitu -0.118 .

hasil yang didapat dari FCM lebih baik dibandingkan hasil yang didapatkan oleh K-Means karena pengelompokan data mendekati baik. Dari perhitungan Standard Deviation, nilai rata-rata pada algoritma $K$ Means sebesar 0.0942 lebih besar dibandingkan nilai rata-rata yang dihasilkan dari FCM yaitu 0.0918 . Berarti hasil yang diperoleh dari FCM lebih baik dibandingkan K-Means karena semakin kecil nilai Standard Deviation, tingkat keseragaman datanya semakin baik.

Maka algoritma Fuzzy C-Means Clustering merupakan algoritma yang terbaik dalam pengelompokan data puskesmas dalam pelayanan imunisasi bayi dan anak dalam cakupan imunisasi dasar lengkap, dan hasil kelompok data dapat menjadi acuan bagi dinas kesehatan Kabupaten Banyuwangi untuk mendorong puskesmas yang memiliki pelayanan sedang dan rendah untuk dapat meningkatkan layanan imunisasi bagi bayi dan anak-anak pada tahun berikutnya.

Saran untuk penelitian selanjutnya adalah perlu ditambahkan metode optimalisasi dalam algoritma Fuzzy C-Means Clustering dalam penentuan pusat centroid sehingga hasil pengelompokan data puskesmas lebih baik lagi. Kemudian dilakukan pula pengecekan terhadap hal-hal apa saja yang mempengaruhi dalam pemberian imunisasi dasar lengkap pada kelompok puskesmas pada cluster sedang dan rendah sebagai bahan evaluasi agar pemberian imunisasi dapat lebih optimal sehingga penyakit yang dapat dicegah dengan imunisasi dapat ditekan sehingga angka kematian bayi dan anak semakin rendah.

\section{Ucapan Terimakasih}

Kami mengucapkan terima kasih kepada Sekolah Tinggi Ilmu Komputer (STIKOM) PGRI Banyuwangi serta Universitas Bina Insani atas dukungannya dalam penelitian ini, sehingga dapat berjalan dengan baik dan lancar.
[1] Simanjuntak, SM, Nurnisa I. (2019). Peningkatan Pengetahuan dan Sikap Ibu Tentang Imunisasi dengan Pendekatan Promosi Kesehatan Tentang Imuniasi Dasar. Jurnal Media Karya Kesehatan (MKK). Volume 2, No 1.

[2] Hudhah M, Hidajah, AC. (2017). Perilaku Ibu Dalam Imunisasi Dasar Lengkap Di Puskesmas Gayam Kabupaten Sumenep. Jurnal Promkes, Vol. 5, No. 2, hal: 167-180.

[3] Kementrian Kesehatan RI, 2019, Profil Kesehatan Indonesia 2018. Jakarta: Kementerian Kesehatan Republik Indonesia.

[4] Wulansari and Nadjib M., Determinan Cakupan Imunisasi Dasar Lengkap pada Penerima Program Keluarga Harapan. Jurnal Ekonomi Kesehatan Indonesia, 4(1), pp. 1-9, doi: 10.7454/eki.v4i1.3087.

[5] Yunizar, Asriwati, and Hadi A. J., 2018, Perilaku Ibu dalam Pemberian Imunisasi DPT/Hb-Hib di Desa Sinabang Kecamatan Simeulue Timur. Jurnal Kesehatan Global, 1(2), p. 61, doi: 10.33085/jkg.v1i2.3956.

[6] Dinas Kesehatan Kab. Banyuwangi, 2018, Profil Kesehatan Kabupaten Banyuwangi Tahun 2018, Banyuwangi: Pemerintah Kabupaten Banyuwangi Dinas Kesehatan.

[7] Kabupaten Banyuwangi, 2019, Data Seputar Kesehatan, [Online] (Updated 2019)

Tersedia di: https://www.banyuwangikab.go.id/profil/profilkesehatan.html. [diakses 19 September 2002].

[8] Sutoyo H., Banyuwangi Kejadian Luar Biasa (KLB) Difteri, [Online] (Updated 20 Februari 2018)

Tersedia di:

https://radarbanyuwangi.jawapos.com/read/2018/02/20/50883. [diakses 22 September 2020].

[9] Talakua M. W., Leleury Z. A., and Talluta A. W., 2017, Analisis Cluster Dengan Menggunakan Metode K-Means Untuk Pengelompokkan Kabupaten/Kota Di Provinsi Maluku Berdasarkan Indikator Indeks Pembangunan Manusia Tahun 2014. Jurnal Ilmu Matematika dan Terapan, 11(2), pp. 119-128.

[10] Suhaeni C., Kurnia A., and Ristiyanti, 2018, Perbandingan Hasil Pengelompokan Menggunakan Analisis Cluster Berhirarki, KMeans Cluster, dan Cluster Ensemble (Studi Kasus Data Indikator Pelayanan Kesehatan Ibu Hamil). Jurnal Media Infotama, 14(1), pp. 31-38.

[11] Darmawan, Muhimmah I., and Kariyam, 2017, Identifikasi Masalah Kesehatan Di Sulawesi Tenggara, Jurnal Ilmiah Rekam Medis dan Informatika Kesehatan (INFOKES), 7(1).

[12] Rahmawati and Faisal M., 2019, Analisis Cluster untuk Pengelompokan Desa Berdasarkan Indikator Penyakit Diare, Jurnal Saintifik, 5(1), pp. 75-80.

13] Rodiyansyah S. F., 2017, K-Means Dan Fuzzy C-Means Pada Analisis Data Polusi Udara Di Kota X, in: STMIK AMIKOM Yogyakarta. Seminar Nasional Teknologi Informatika dan Multimedia. Yogyakarta, 4 Februari 2017. Indonesia.

[14] Shedthi B. S., Shetty S., and Siddappa M., 2017, Implementation and Comparison of K-Means and Fuzzy C-Means Algorithms for Agricultural Data. in: Gnanamani College of Technology, International Conference on Inventive Communication and Computational Technologies (ICICCT), Coimbatore, 10-11 March 2017. India.

[15] Ramya T. B., 2018, Disease Prediction System Using Fuzzy CMeans Algorithm. International Journal of Engineering Research \& Technology (IJERT), 6(3), pp. 1-5.

[16] Simhachalam B. and Ganesan G., 2014, Possibilistic fuzzy Cmeans clustering on medical diagnostic systems. in: Sri Jayachamarajendra College of Engineering, Proceeding 2014 International Conference on Contemporary Computing and Informatics (IC3I), Mysore, 27-29 November 2014, India.

[17] Agustina N. and Prihandoko, 2018, Perbandingan Algoritma KMeans dengan Fuzzy C Means Untuk Clustering Tingkat Kedisiplinan Kinerja Karyawan (Studi Kasus: Sekolah Tinggi Teknologi Bandung). Jurnal RESTI (Rekayasa Sistem dan Teknologi Informasi), 2(3), pp. 621-626, doi: 10.29207/resti.v2i3.492.

[18] Ramadhan A., Efendi Z., and Mustakim, 2017, Perbandingan KMeans dan Fuzzy C-Means untuk Pengelompokan Data User 
Knowledge Modeling. in: UIN Sultan Syarif Kasim Riau, Seminar Nasional Teknologi Informasi, Komunikasi dan Industri (SNTIKI) 9, Pekanbaru, 18-19 Mei 2017, Indonesia.

[19] Wahyuni I., Auliya Y. A., Rahmi A., and Mahmudy W. F., 2016, Clustering Nasabah Bank Berdasarkan Tingkat Likuiditas Menggunakan Hybrid PSO K-Means. Jurnal Ilmiah Teknologi dan Informasi ASIA (JITIKA), 10(1), pp. 24-33.

[20] Sangeetha J. and Prakash V. S. J., 2017, An Efficient Inclusive Similarity Based Clustering (ISC) Algorithm for Big Data, in: Institute of Electrical and Electronics Engineers (IEEE), Proceeding 2nd World Congress on Computing and Communication Technologies (WCCCT), Tiruchirappalli, 2-4 Februari 2017, India.

[21] Chusyairi A. and Saputra P. R. N., 2019, Pengelompokan Data Puskesmas Banyuwangi Dalam Pemberian Imunisasi Menggunakan Metode K-Means Clustering, Telematika, 12(2), pp. 139-148, doi: 10.35671/telematika.v12i2.848.

[22] Syarif R., Furqon M. T., and Adinugroho S., 2018, Perbandingan Algoritme K-Means Dengan Algoritme Fuzzy C Means (FCM) Dalam Clustering Moda Transportasi Berbasis GPS. Jurnal Pengembangan Teknologi Informasi dan Ilmu Komputer, Universitas. Brawijaya, 2(10), pp. 4107-4115.

[23] Kusuma B. M. A. and Theresia O., Implementasi Program Jaminan Pelayanan Kesehatan Masyarakat Banyuwangi (JPKMB) Dalam Mewujudkan Pelayanan Kesehatan Primer Bagi Seluruh Lapisan Masyarakat. The Indonesian Journal of Public Administration (IJPA), 2(1), pp. 103-117. 